\title{
Serum Mediated Killing of Three Group D Salmonellas
}

\author{
By F. M. COLLINS* \\ Microbiology Department, University of Adelaide, South Australia
}

(Accepted for publication 31 August 1966)

\begin{abstract}
SUMMARY
Salmonella enteritidis, $S$. pullorum and $S$. gallinarum were found to be sensitive to complement-mediated killing by fresh normal human serum but far less so to sera of the mouse, rat or rabbit. S. pullorum but not $S$. gallinarum was sensitive to the microbicidal activity of adult fowl serum. S. enteritidis was slightly sensitive to the latter serum. Day-old-chick serum was unable to kill either $S$. gallinarum or $S$. pullorum even when undiluted serum was used. When human serum was absorbed at $4^{\circ}$ by dense suspensions of dead organisms it was found that all antimicrobial activity against the three organisms was absorbed only when the homologous organism was used as the absorbing strain. This suggests that minor somatic antigenic differences occur between the three related organisms. S. pullorum was extremely sensitive to the action of monospecific rabbit antisera. However, serum concentrations which were highly effective against $S$. pullorum were less effective for $S$. enteritidis. Even highly microbicidal serum concentrations were unable to kill $100 \%$ of the $S$. enteritidis within the time period of the test. The relevance of these findings to the known differences in the virulence of these three salmonellas for the mouse and the chicken is discussed.
\end{abstract}

\section{INTRODUCTION}

The high degree of resistance of some animals to bacteria which may be highly pathogenic for a closely related host species presents a fascinating problem. The factors involved in this so-called 'natural' immunity are known to be complex and variable, depending upon the nature of the parasite and host. For instance, a definite correlation has been shown between the presence of $\beta$-lysins in the blood and resistance to Bacillus anthracis and to infections by some other Gram-positive bacteria (Topley \& $W i l s o n ' s$ Principles, 1964). However, the $\beta$-lysins do not appear to be active against Gram-negative bacteria. In general, resistance to infection by the latter organisms shows no simple correlation with serum factors.

The microbicidal activity of fresh serum taken from apparently normal animals has been known for many years (Mackie \& Finkelstein, 1928; Gordon \& Carter, 1932), but it is only in recent years that the dual requirement for specific antibody and complement has been clearly established (Skarness \& Watson, 1957). Adler (1953) showed that natural antibody present in the serum of uninfected animals combined specifically with surface antigens of susceptible bacteria. These antibodies were probably produced in response to cross-reacting bacterial antigens present in the normal enteric flora of most animals. Recently, Michael, Whitby \& Landy (1962) demonstrated microbicidal antibody specific for Escherichia coli and Salmonella typhi in normal mice. They

\footnotetext{
* Present address: Trudeau Institute, Saranac Lake, New York, U.S.A.
} 
showed that serum from newborn mice did not contain antibacterial antibody but rapidly acquired it within a week of birth. Fisher \& Manning (1958) reported that normal human serum contained antibodies against E. coli, Proteus species and Staphylococcus aureus, but not against $S$. typhimurium, Klebsiella pneumoniae or Streptococcus pyogenes. These workers suggested that there may be a significant correlation between the resistance of the host to infection by some bacteria and the presence of specific antibody in the circulating blood. Although a number of such correlations have been reported in the past, no general pattern has emerged, and recently Muschel, Chamberlin \& Osawa (1958) re-emphasized that resistance to a particular disease cannot be explained simply in terms of an in vitro phenomenon. Nevertheless, there exist instances in which a definite correlation has been shown between the degree of microbicidal activity in the serum and resistance to a particular pathogen. In these circumstances serum-mediated killing may be a contributory factor to host resistance.

In the present study, considerable differences in the serum sensitivity of three closely related salmonella strains were observed. In view of the known differences in virulence of the three strains for mice and chickens, a further investigation was made of their sensitivity to serum-mediated killing.

\section{METHODS}

Organisms. The strains of organisms used were described elsewhere (Collins, Mackaness \& Blanden, 1966). They were grown on Oxoid blood base agar slopes enriched with $1.0 \%(\mathrm{w} / \mathrm{v})$ Casamino acids and $0.1 \%$ yeast extract (Oxo Ltd., London). Fresh subcultures were made at 3-month intervals. After four transfers the culture was discarded and a fresh freeze-dried culture was opened.

Sera. Fresh human group AB serum was obtained from the Red Cross Blood Bank, Adelaide, dispensed in $5 \mathrm{ml}$. ampoules and stored at $-20^{\circ}$ until required. Before use the serum was thawed and absorbed at $4^{\circ}$ for $60 \mathrm{~min}$. with $2 \mathrm{mg}$. dry wt. of the appropriate strain of bacteria (previously killed by heating to $56^{\circ}$ for $30 \mathrm{~min}$.) per $\mathrm{ml}$. of serum. The bacteria were removed in a Serval refrigerated centrifuge (model RC2) and the absorption procedure was repeated. Absorbed serum was used immediately as an added complement source where indicated in the text. Haemolytic complement titrations, carried out before and after absorption (Mackie \& McCartney, 1962), showed a decrease in titre of no more than one tube after the double absorption. Fresh fowl and chicken sera was obtained by heart puncture from certified Salmonella pullorum-free stock (Government Poultry Farm, Parafield). They were immediately used and were not enriched with absorbed human complement-containing serum. Mice were bled by the method described by Rosenberg \& Tachibana (1962). Monospecific $\mathrm{H}$ and $\mathrm{O}$ rabbit immune sera were prepared as recommended by Kauffmann (1954). These sera were heated at $56^{\circ}$ for $30 \mathrm{~min}$. and stored at $-20^{\circ}$ until required. Absorbed human serum (1/10) was used as a source of complement in all bactericidal tests involving rabbit immune sera.

Bactericidal tests. Test sera were diluted in Davis \& Mingioli (1950) basal medium without the addition of glucose. Where required, an equal volume of absorbed human serum was added to each sample (final dilution 1/10). Heated human and test sera ( $56^{\circ}$ for $30 \mathrm{~min}$.) controls were always included. After equilibration at $37^{\circ}$ the serum dilutions were inoculated with 1000-2000 logarithmic-phase bacteria. Samples were 
removed after thorough mixing and colony counts made at $0,20,40$ and $60 \mathrm{~min}$. The end titre was taken as the highest dilution of serum which (in the presence of excess complement) resulted in $50 \%$ killing within $1 \mathrm{hr}$.

\section{RESULTS}

Microbicidal activity of fresh normal serum for Salmonella enteritidis, S. pullorum and S. gallinarum

The microbicidal titres of fresh serum from five animal species showed considerable variation when tested against the three strains of Salmonella (Table 1). Whereas the rabbit and rat sera showed little or no activity against Salmonella enteritidis, human serum was active against all three strains. The absence of activity in rabbit serum was due to a lack of specific antibody, since fresh serum from rabbits immunized with a heat-killed vaccine of $S$. enteritidis was highly bactericidal for this organism. Fresh mouse serum was not microbicidal for $S$. enteritidis even when absorbed human complement was added. Salmonella gallinarum was killed by $1 / 4$ dilution of mouse serum, but variable results were obtained when the test was repeated at a $1 / 5$ dilution. Salmonella pullorum was sensitive to a $1 / 5$ to $1 / 10$ dilution of mouse serum.

Table 1. Antimicrobial titres against three salmonellas of fresh normal sera obtained from animal species

\begin{tabular}{lccc} 
& \multicolumn{3}{c}{ Inverse of end titre* } \\
\cline { 2 - 4 } Normal sera & S. enteritidis & S. gallinarum & $S$. pullorum \\
Human & 20 & 20 & 40 \\
Rabbit & 0 & 0 & 5 \\
Rat & 2 & 10 & 0 \\
Mouse & 0 & 4 & $5-10$ \\
Chicken & 5 & 0 & 0 \\
1-day & 5 & 0 & 5 \\
7-day & 10 & 0 & 20 \\
30-day & 8 & 0 & 16 \\
90-day & & & \\
* No extraneous source of complement was used in these tests.
\end{tabular}

Fresh adult fowl serum was microbicidal for both Salmonella enteritidis and $S$ pullorum but not for $S$. gallinarum. This contrasted sharply with the titres obtained for day-old chicken serum (Table 1) which did not kill either $S$. pullorum or $S$. gallinarum even when undiluted serum was tested. The progressive change in the microbicidal titre of a serum pool taken from 20 maturing chickens is recorded in Table 1 . Killing curves for the three Salmonella strains tested against 1-day chick and 3-month fowl sera are recorded in Figs. 1-6. The adult fowl serum was bactericidal for both $S$. enteritidis and $S$. pullorum at a dilution of $1 / 10$, but as many as $20 \%$ of the $S$. enteritidis still survived after $60 \mathrm{~min}$. This could be compared with less than $1 \%$ survival of $S$. pullorum in this time. The $10-20 \%$ survival rate for $S$. enteritidis occurred even when undiluted serum was used. Addition of fresh serum to the tube after $60 \mathrm{~min}$. had little further effect on the viability of the survivors. After culture in broth, the survivors yielded a population of bacteria which gave a killing curve almost 
identical to the original. Thus, the serum treatment had not selected a stable population inherently more resistant to serum-mediated killing. The significance of this finding will be discussed later.

\section{Bactericidal activity of absorbed rabbit sera for the three strains}

The observed variation in the rate and extent of killing of the three Salmonella strains by normal serum justified a further examination of the bactericidal reaction with absorbed rabbit serum specific for somatic antigens 0-9 or 0-12. Absorbed human serum was added as a complement source throughout. Preliminary experiments

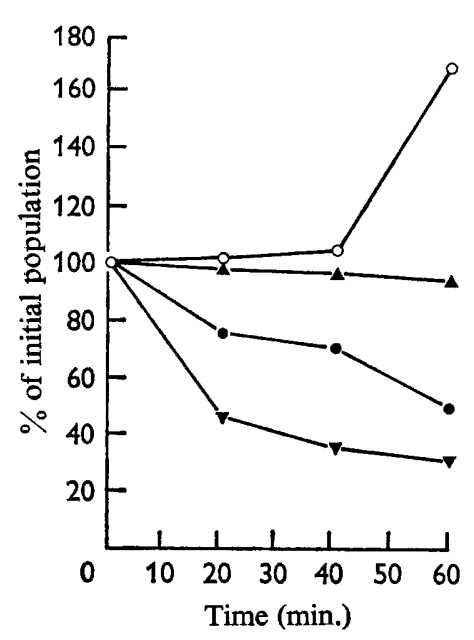

Fig. 1

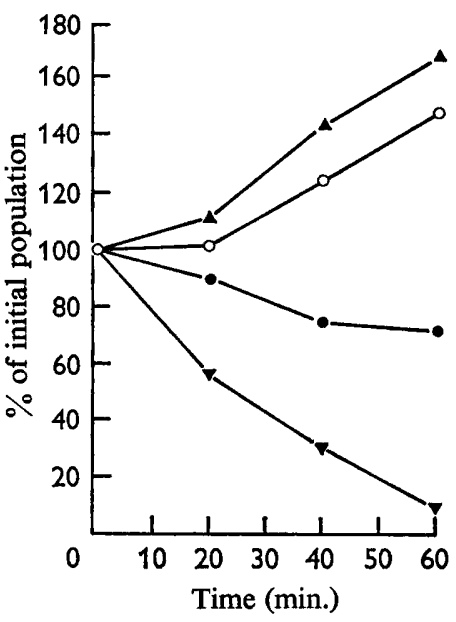

Fig. 2

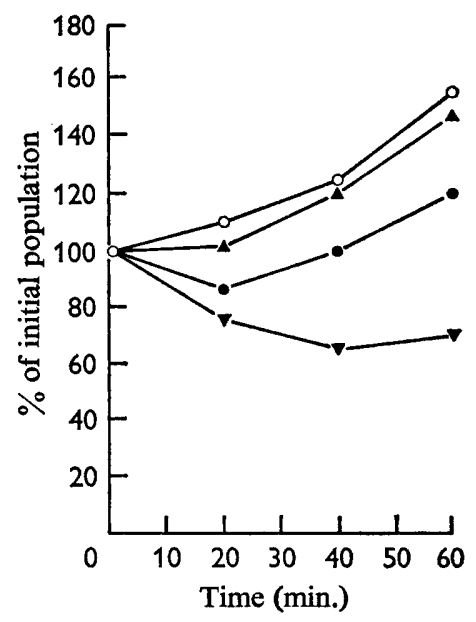

Fig. 3

Fig. 1. Killing curves for Salmonella enteritidis in decreasing concentrations of fresh 1-day chicken serum. The control contained a $1 / 5$ dilution of serum heated to $56^{\circ}$ for $30 \mathrm{~min}$. Absorbed human serum (1/10) was added as a source of complement. $\nabla-\nabla, 1 / 2$ serum; -D, $1 / 5$ serum; $\Delta-\Delta, 1 / 10$ serum $\bigcirc-O$, control.

Fig. 2. Killing curves for Salmonella pullorum in decreasing concentrations of fresh 1-day chicken serum. Absorbed human serum $(1 / 10)$ added as a source of complement. Symbols as for Fig. 1.

Fig. 3. Killing curves for Salmonella gullinarum in decreasing concentrations of fresh 1-day chicken serum. Absorbed human serum (1/10) added as a source of complement. Symbols as for Fig. 1.

Table 2. The microbicidal activity of human serum pre-absorbed at $4^{\circ}$ by increasing amounts of three Salmonellas

\begin{tabular}{|c|c|c|c|c|}
\hline \multirow{2}{*}{\multicolumn{2}{|c|}{ Absorbing suspension }} & \multicolumn{3}{|c|}{ Inverse of microbicidal titre* } \\
\hline & & S. enteritidis & S. gallinarum & S. pullorum \\
\hline \multirow[t]{2}{*}{ Nil } & & 20 & 20 & 40 \\
\hline & $((2 \mathrm{mg} . / \mathrm{ml}))$ & 2 & 5 & 10 \\
\hline \multirow[t]{2}{*}{ S. enteritidis } & (4 mg./ml.) & 0 & 5 & 5 \\
\hline & $(10 \mathrm{mg} . / \mathrm{ml})$. & $\mathbf{0}$ & 0 & $0-2$ \\
\hline S. gallinarum & $(4 \mathrm{mg} . / \mathrm{ml})$ & 5 & 0 & 10 \\
\hline S. pullorum & ( $4 \mathrm{mg} . / \mathrm{ml})$. & 10 & 20 & 0 \\
\hline
\end{tabular}

* No extraneous source of complement was used in these tests. 
showed that absorption of the human serum with dense suspensions of Salmonella enteritidis rapidly removed all activity for $S$. enteritidis, but that at least five times as many bacteria were necessary to remove all activity against $S$. gallinarum and $S$. pullorum (Table 2). Similar results were observed when S. gallinarum or $S$. pullorum were used for the cross-absorptions. Absorption of human serum in these tests was therefore always made with killed suspensions of the organism to be used in the final test.

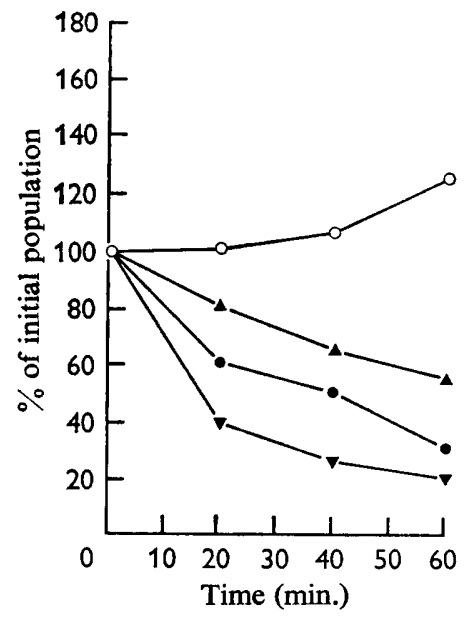

Fig. 4

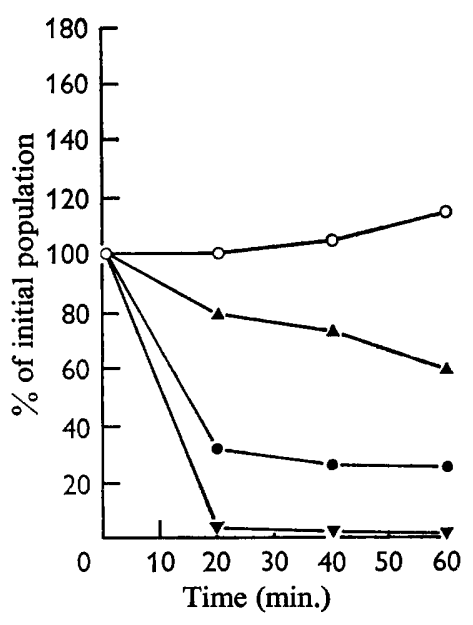

Fig. 5

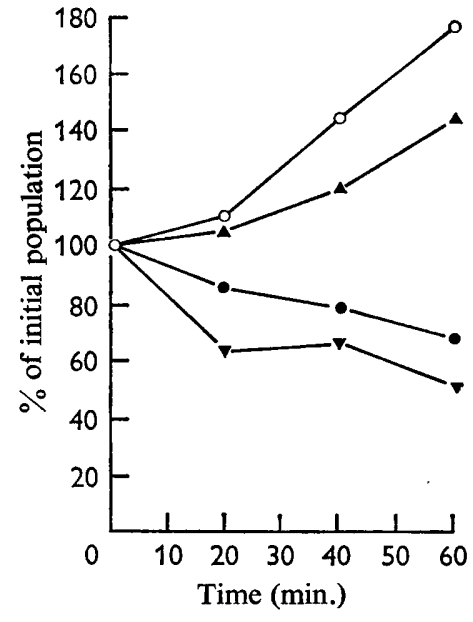

Fig. 6

Fig. 4. Killing curves for Salmonella enteritidis in decreasing concentrations of fresh adult fowl serum. No extraneous complement source added. $\nabla-\nabla, 1 / 5$ serum; $0-0,1 / 10$ serum; $\Delta-\Delta, 1 / 20$ serum; $O-O$, control.

Fig. 5. Killing curves for Salmonella pullorum in decreasing concentrations of fresh adult fowl serum. No extraneous complement source added. $\nabla-\nabla, 1 / 10$ serum; $-0,1 / 20$ serum; $\Delta-\mathbf{A}, 1 / 40$ serum; $\mathrm{O}-\mathrm{O}$, control.

Fig. 6. Killing curves for Salmonella gallinarum in decreasing concentrations of fresh adult fowl serum. No extraneous complement source added. Symbols as for Fig. 5.

Table 3. Microbicidal activity of monospecific rabbit antisera

\begin{tabular}{lccc} 
& \multicolumn{3}{c}{ Inverse of end titre* } \\
\cline { 2 - 4 } Serum & S. enteritidis & S. gallinarum & S. pullorum \\
Unabsorbed immune serum & $10^{4}$ & $10^{5}$ & $10^{6}$ \\
Specific 'H' (g.) & $10 \dagger$ & - & - \\
Anti-0-1 & 50 & - & - \\
Anti-0-9 & $10^{3}$ & $10^{5}$ & $10^{5}$ \\
Anti-0-12 & $5 \times 10^{2}$ & $10^{4}$ & $10^{5}$
\end{tabular}

* Specifically absorbed human serum $(1 / 10)$ was added as complement source throughout. $\dagger$ This activity was probably due to traces of incompletely absorbed ' $O$ ' antibody.

$-=$ not done.

The microbicidal titres of the monospecific rabbit serum are recorded in Table 3. Salmonella gallinarum and $S$. pullorum were 10 to 100 times more sensitive to monospecific antibody than was $S$. enteritidis. Essentially similar results were obtained with absorbed serum obtained from fowls vaccinated with heat-killed $S$. pullorum. 


\section{DISCUSSION}

For the most part, early work failed to show any consistent correlation between the resistance of an animal species to infection and the microbicidal activity of the serum to the infecting organism (Skarnes \& Watson, 1957). This is hardly surprising in view of the complex interactions which occur between host and parasite during the evolution of an infection. The failure of both rabbit and rat serum to kill Salmonella enteritidis even though both animals are totally resistant to infection by this organism exemplify this lack of correlation. However, microbicidal activity of sera from mice and developing chickens shows a closer correlation with the natural susceptibility of these animals to infection with the three test strains of Salmonella. Thus, the serum of the 1-day chick, which is susceptible to infection by both $S$. pullorum and S. gallinarum, was unable to kill either strain of organism in vivo when diluted more than 1 in 2 , even in the presence of excess complement. An extraneous source of complement was thought essential for testing the 1-day chick sera. This was suggested by the finding of Dr K. Karthigasu (personal communication) that chick embryos were unable to kill even an avirulent variant of $S$. gallinarum. It was shown that bactericidal activity of the developing chick serum correlated well with its haemolytic complement value. Shortly after hatching the haemolytic complement activity of the chicken serum increased and serum-mediated killing could then be detected.

Adult fowls were susceptible to Salmonella gallinarum infections but not to $S$. pullorum; and the increased microbicidal activity of the adult birds' sera for S. pullorum, but not for the antigenically similar $S$. gallinarum, was therefore very interesting. Since cell walls of both organisms contain approximately equal amounts of lipopolysaccharide possessing antigen 0-9 and 0-12 specificity, the bactericidal activity of normal sera for these strains must depend on antibodies specific for antigens other than those listed in the Kauffmann-White scheme. The observed differences in the absorptive abilities of suspensions of the three Salmonella strains for the microbicidal antibody present in normal human serum (Table 2) lends further weight to the argument that minor cell-wall antigens may be important factors in determining the susceptibility of Gram-negative bacteria to complement-mediated killing.

Salmonella pullorum appeared to be exquisitely sensitive to serum killing, whereas S. enteritidis was relatively resistant. Furthermore, almost $100 \%$ of the S. pullorum cells were killed, in 20 min. or less, by concentrations of antibody which could kill only $80 \%$ of the $S$. enteritidis in $60 \mathrm{~min}$. Specific anti-9 antibody was still bactericidal for $S$. pullorum and $S$. gallinarum at dilution of $1 / 100,000$, whereas a $1 / 1000$ dilution was needed to kill $S$. enteritidis.

Rough strains of Gram-negative bacteria have been reported in general to be more susceptible to the microbicidal action of normal serum than are the antigenically smooth parent strains (Muschel et al. 1958). Suspensions of the Salmonella pullorum strain used in this study were therefore tested for smoothness. By the slide-agglutination test, the suspension was stable in the presence of $0.1 \%$ acriflavine (Mackie \& McCartney, 1962) and only slight auto-agglutination was observed when the organisms were incubated at $56^{\circ}$ overnight. The extreme sensitivity of $S$. pullorum to serummediated killing could not, therefore, be explained in terms of S-R variation.

One further possible explanation for the observed differences in sensitivity might be that the antigenic groups on Salmonella pullorum cell walls are optimally situated for 
complement-mediated killing, whereas in $S$. enteritidis (and to a lesser extent in $S$. gallinarum) fewer such sites are available. However, this could not explain the observed differences in the final percentage kill of the three test organisms. Nevertheless, the correlation between the increasing degree of serum activity in developing fowls and the corresponding increase in resistance to infection may be causally related. Investigation of the levels of specific microbicins in the sera of other animal species which show similar striking differences in their susceptibility to infection by antigenically related Salmonella may reveal similar correlations to that found in the present study.

I wish to thank Mr R. Walsh for his excellent technical assistance during this study. I am indebted to the Red Cross Blood Bank, Adelaide, for generously supplying the human serum used.

\section{REFERENCES}

AdLER, F. L. (1953). Bactericidal action of normal sera against a strain of Salmonella typhosa. $J$. Immunol. 70, 69.

Collins, F. M., Mackaness, G. B. \& Blanden, R. V. (1966). Infection immunity as the basis of resistance to Salmonella infections. J. exp. Med. 124, 601.

Davis, B. D. \& MingIOLI, E. S. (1950). Mutants of E. coli requiring methionine and vitamin $\mathbf{B}_{12}$. J. Bact. 60, 17.

Fisher, M. W. \& MANNING, M. C. (1958). Studies on the immuno-therapy of bacterial infections. I. The comparative effectiveness of human globulin against various bacterial species in mice. $J$. Immunol. 81, 29.

Gordon, J. \& CARTER, H. S. (1932). The bactericidal power of normal serum. J. Path. Bact. 25, 549.

KauffmanN, F. (1954). The Enterobacteriaceae, 2nd ed. Copenhagen: E. Munksgaard.

MACKIE, T. J. \& FINKELSTEIN, M. H. (1928). The bactericidins of normal serum: Their characters, occurrence in various animals and the susceptibility of different bacteria to their action. J. Hyg., Camb. 32, 1.

Mackie and McCartney's Handbook of Bacteriology. (1962). Ed. by R. Cruickshank. 10th ed. London: Livingstone, Ltd.

MichaEL, J. G., WhITBY, J. L. \& LANDY, M. (1962). Studies on natural antibodies to Gram-negative bacteria. J. exp. Med. 115, 131.

Muschel, L. H., Chamberuin, R. H. \& Osawa, E. (1958). Bactericidal activity of normal serum against bacterial cultures. I. Activity against Salmonella typhi strains. Proc. Soc. exp. Biol. Med. 97, 376.

Rosenberg, L. T. \& TACHiBana, D. K. (1962). Activity of mouse complement. J. Immunol. 89, 861.

SKARNESS, R. C. \& WATSON, D. W. (1957). Antimicrobial factors of normal tissues and fluids. Bact. Rev. 21, 273.

Topley and Wilson's Principles of Bacteriology and Immunity. (1964). 5th ed. Ed. by G. S. Wilson and A. A. Miles. London: Edward Arnold and Co. 